\title{
Phytochemical Screening of Leaves from Mangifera indica and Morus alba for Bioactive Compounds
}

\author{
${\text { Muhammadi }{ }^{*} \text {, Shabina Shafiq }}^{2}$, Faisal Hussain ${ }^{3}$ \\ ${ }^{1}$ Centre for Bioresource Research, Islamabad, Pakistan. \\ ${ }^{2}$ HEJ Research Institute of Chemistry, University of Karachi, Karachi-75270. Pakistan. \\ ${ }^{3}$ Department of Botany, Federal Urdu University of Arts, Science and Technology, Gulshan-e-Iqbal Campus, Karachi, Pakistan.
}

\section{ART I C L E I N F O}

\section{Article History}

Received: April 09, 2020

Revised: July 13, 2020

Accepted: August 04, 2020

\section{Keywords}

Antimicrobial

Antioxidant

Antiurease

Anthelmintic

Phytochemical
A B S T R A C T

The aqueous, methanol and DMSO extracts from leaves of Mangifera indica and Morus alba were screened for bioactive compounds. Antimicrobial activity and MIC (mg/ml) were determined using agar-well diffusion and serial dilution methods respectively against human pathogenic bacteria and fungi. Antioxidant activities (\%) were determined against DPPH free radicals, superoxide anion and $\mathrm{Fe}+2$ whereas antiurease activity (\%) was by indophenol method. The time taken to set paralysis and death of Pheritima posthuma was observed after released into extract. Phytochemical analysis detected carbohydrates, alkaloids, phenols, flavonoids, terpenoids, saponins, tannins, steroids, resins, anthraquinones, cardiac glycosides and phlobatannins. All extracts more or less showed the activity against Gram-positive and -negative bacteria producing zone of inhibition $15 \pm 0.57$ to $43.66 \pm 0.66 \mathrm{~mm}$ and MIC values $13 \pm 1.64$ to $100 \pm 0.35 \mathrm{mg} / \mathrm{ml}$. Similarly, for fungi, zone of inhibition and MIC values were $9 \pm 0.57$ to $34 \pm 0.57 \mathrm{~mm}$ and $23 \pm 1.25115 \pm 0.55 \mathrm{~g} / \mathrm{ml}$ respectively. Activities against DPPH, superoxide anion and $\mathrm{Fe}+2$ free radicals were found $13.68 \pm 0.74$ to $93.70 \pm 0.76 \%$, $50.23 \pm 0.43$ to $95.7 \pm 0.21 \%$ and $52.76 \pm 0.23$ to $98.82 \pm 0.42 \%$ respectively, of these, the maximum activities surpassed the n-propyl gallate $(91.31 \%)$ and EDTA (98.05\%). Similarly, urease was also inhibited (33 to 95.23\%) by all extracts. All extracts were also caused paralysis followed by subsequent death (13.5/26.87 to 39/60.06 $\mathrm{min}$ ) of $P$. posthuma, of these methanolic extract from M. indica was least than that by albendazole (30.45/52 $\mathrm{min})$ and piperazine citrate $(14.35 / 36 \mathrm{~min})$. The results provide scientific basis for traditional use of these extracts as affordable strategies for treatments of infectious, inflammatory and degenerative diseases, caused by bacteria, fungi, free radicals, urease and helminths.

Corresponding Author: Muhammadi

Email: muhammadi12@yahoo.com

(C) The Author(s) 2020.

\section{INTRODUCTION}

The use of medicinal plants as herbal remedies for the treatment of diseases and maintenance of health is an effective ancient practice since civilization on earth. Interestingly, they are still widely used for same purposes all over the world especially individuals and communities from rural areas of developing and third world countries who have difficulty in gaining access to modern medicines use medicinal herbs and plants, as an alternative to conventional treatment for their recovery (Doughari and Manzara 2008; Muanda et al., 2011). According to World health organization (1995) about 80 $\%$ of the world population is taking interest in indigenous medicinal plant remedies. The development 
and prevalence of multidrug resistance microbial pathogens, and the recent appearance of strains with reduced susceptibility to currently being used antibiotics are increasing at an alarming rate worldwide. Another big concern is that the drug-resistant bacteria and fungal pathogens have further complicated the treatment of infectious diseases especially in AIDS and cancer patients (Rajendran and Ramakrishnan 2009). Besides this, the drug development process is very costly, pharmaceutical companies often concentrate on finding antimicrobials similar to the ones already found to reduce the risk of producing an unmarketable drug. This means that it is easy for microorganisms to develop resistance to a similar drug to which it already has resistance (Cunha 1998). Therefore, there is a continuous and urgent need to search for new infectionfighting strategies (Sieradzki 1999). Free radicals contribute to more than one hundred disorders in humans including atherosclerosis, arthritis, ischemia and reperfusion injury of many tissues, central nervous system injury, gastritis, cancer, and AIDS. Free radicals due to environmental pollutants, radiation, chemicals, toxins, deep-fried and spicy foods as well as physical stress, cause depletion of immune system antioxidants, change in gene expression, and induce abnormal proteins. The oxidation process is one of the most important routs for producing free radicals in food, drugs and even living systems. Currently available synthetic antioxidants like butylated hydroxyanisole, butylated hydroxy toluene, tertiary butylated hydroquinon and gallic acid esters, have been suspected to cause or prompt negative health effects. Hence, strong restrictions have been placed on their application and there is a trend to substitute them with naturally occurring antioxidants (Pourmorad et al., 2006; Mathur et al., 2010). Urease the most prominent protein component of several microorganisms (Helicobacter pylori, Proteus mirabilis, P. vulgaris, and Ureaplasme urealyticum), is involved in hydrolysis of urea into ammonia which neutralizes acids of stomach, thus infections of gastrointestinal and urinary tract. The formation of struvite stones in urinary tract is associated with urea-splitting U. urealyticum, which may lead to the chronic inflammation of kidney and its pelvis. Moreover, urinary catheter obstruction in patients causes colonization of urease-producing microorganisms, essentially P. mirabilis. Overproduction of ammonia by infectious microorganisms may contribute to ammonia encephalopathy or hepatic coma. Furthermore, high concentration of ammonia disturbs mucosal permeability, in particular, hydrogen ions passage through mucosal surface and causes the formation of peptic ulcers (Estiu and Mer 2004; Khan et al., 2010). H. pylori whole cell can stimulate an oxidative burst in human neutrophils which leads to formation of the highly toxic product monochloramine (Tahseen et al., 2010). Parasitic worms are also challenging pathogens for human beings, they pose a major threat to public health and contribute to prevalence of malnutrition, anaemia, eosinophilia, and pneumonia (Kulkarni et al., 2010). Unfortunately, currently being used anthelmintic drugs have adverse effects and their indiscriminate use is leading to resistance of parasites (Devi et al., 2009), therefore, there is a foremost problem in treatment of helminths diseases. Hence there is an increasing demand towards natural anthelmintics. Therefore, it is important to search for novel therapeutic agents, other than synthetic, that are both highly effective and safe.

On the other hands, plants are known to provide a rich source of anthelmintics, antibacterial, antifungal, urease inhibitors and antioxidants. Though much work has been done on ethno-medicinal plants, but there is still needed to seek plants with medicinal value to combat diseases. Because medicines from plants are considered as time tested, effective, cheap, easily available, affordable, and safe for both human use and environment friendly (Iwu et al., 1999; Fazly-Bazzaz et al., 2005. In contrast to current combination therapies, however, plant-based drugs contain a mixture of multiple components thereby saving considerable time and expense (Karnath 2002). The WHO (1995) has supported and recommended the use of traditional medicine provided they are proven to be efficacious and safe. Therefore, the present study was undertaken to screen the bioactive compounds in leaves of some indigenous fruiting plants which are untapped sources of medicines and to evaluate them for antibacterial, antifungal, antioxidant, urease inhibition and anthelmintic activities.

\section{METHODS AND MATERIAL}

\section{Collection and preparation of plant material}

Fresh, healthy, and mature leaves of Mangifera indica and Morus alba were collected from Garden of the Sindh Horticulture Research Institute, Mirpurkhas. The leaf samples were collected in sterile polyethylene bags. 
Leaves were washed once with tap water, rinsed with distilled water, and air-dried at room temperature. Airdried leaves were chopped into small pieces and ground into fine powder in liquid nitrogen using porcelain mortars and pestles.

\section{Extraction procedure}

Powder of air-dried leaves (100 g) was transferred in $1000 \mathrm{ml}$ blue cap Schott Duran (GL 45) bottles containing $500 \mathrm{ml}$ water, methanol, and dimethyl sulfoxide (DMSO), and samples were completely submerged in the solvents. The capped bottles were kept in a shaking water bath at $50{ }^{\circ} \mathrm{C}$ for $48 \mathrm{hrs}$. After that, the extracts were filtered using Whatman filter paper no. $2(125 \mathrm{~mm})$ and each filtrate was centrifuged at $10000 \mathrm{rpm}$ for 10 minutes. Supernatants were collected in glass beakers, concentrated under reduced pressure at $45{ }^{\circ} \mathrm{C}$ and freeze-dried. The extracts were stored in universal sampling vials of known weight under codes aqueous extract (AE), DMSO extract (DE) and methanol extract (ME) at $4{ }^{\circ} \mathrm{C}$ until use. The solvents were removed under the vacuum at temperature below $50{ }^{\circ} \mathrm{C}$ and the extracts were freeze-dried. For activity assay, the required quantity of each extract was dissolved in DMSO (Khumpook et al., 2018).

\section{Phytochemical screening}

Phytochemical screening of each extract for presence and absence of carbohydrates, alkaloids, phenols, flavonoids, terpenoids, saponins, tannins, steroid, resins, anthraquinones, cardiac glycosides and phlobatannins using standard procedures as described by Sofowora et al., (1993) and Radhika et al., (2008).

\section{Test Microbial Pathogens}

Clinical strains of Gram-positive (Bacillus subtilis (Gu et al., 2019), B. cereus, Staphylococcus aureus, S. pyogenes and S. pneumoniae), Gram-negative (Escherichia coli, $\mathrm{H}$. pylori Pseudomonas aeruginosa, Shigella flexenari, Klebsiella pneumoniae and Salmonella typhimurium) bacteria and fungi (Trichophyton longifusus, Candida albicans, Aspergillus flavus, Microsporum canis, Fusarium solani (Daba et al, 2016) and Candida glaberata) acquired from Plant Bioscreening Laboratory of HEJ Research Institute of Chemistry, University of Karachi, Pakistan. Prior to test, each bacterial strain was sub-cultured on nutrient agar medium and incubated at $37{ }^{\circ} \mathrm{C}$ for $24 \mathrm{hrs}$. Fungal strains were sub-cultured on sabouraud dextrose agar (SDA) medium and incubated at $28{ }^{\circ} \mathrm{C}$ for 15 days.
The freshly revived test microbes were preserved at $4{ }^{\circ} \mathrm{C}$ in aliquots.

\section{Assay for Antimicrobial Activity}

The antimicrobial activity of each plant extract was determined using agar-well diffusion method (Coolborn and Bolatito 2010: Duru and Oyedineke 2010). With a sterile cork borer, wells of equal depth $(\Delta=5 \mathrm{~mm}$ diameter) were dug on solidified nutrient agar and SDA media plates respectively for test bacterial and fungal pathogens. $0.2 \mathrm{ml}$ of the log phase culture of test bacterial strains was seeded on the surface of nutrient agar medium while that of fungal strains was seeded on SDA medium. The wells were aseptically filled up separately with the extracts $(0,50,10,20,30,50$ and $100 \mathrm{mg} / \mathrm{ml})$ avoiding splash and overfilling. Imipenum (thienamycinformamidine) $(15 \mu \mathrm{g} / \mathrm{ml})$ was used as broad-spectrum antibacterial standard whereas miconazol $(150 \mu \mathrm{g} / \mathrm{ml})$ and amphoterocin B $(30 \mu \mathrm{g} / \mathrm{ml})$ were used as broad spectrum antifungal standard drugs. For every experiment, a sterility check ( $5 \% \mathrm{v} / \mathrm{v}$ aqueous DMSO and medium), negative control (5\% v/v aqueous DMSO, medium and inoculum) and positive control ( $5 \%$ aqueous DMSO, medium, inoculum and standard drug) were included. The positive antibacterial and antifungal activities were established by the measurable zones of inhibition after incubation at $37^{\circ} \mathrm{C}$ for $48 \mathrm{hrs}$ and 15 days for bacteria and fungi respectively.

\section{Minimum Inhibitory Concentration}

The extracts that showed antimicrobial activity were later tested to determine the minimal inhibitory concentration (MIC) for each bacterial and fungal strain. MIC was determined according to the method of Sahm, and Washington (1990) and Radhika et al., (2008). Two hundred milli gram extract was dissolved in $1 \mathrm{~mL}$ of nutrient broth and subsequently transferred. One millilitre from the first test tube to the next test tube and this continues up to the seventh test tube. Then $20 \mu \mathrm{l}$ fresh cultures of bacterial and fungal test strains were inoculated into each test tube, mixed thoroughly, and incubated at $37^{\circ} \mathrm{C}$ for $48 \mathrm{hrs}$ and 15 days respectively. The inoculum from tubes that showed no growth was subcultured onto extract free agar plates, incubated for another $48 \mathrm{hrs}$ at $37^{\circ} \mathrm{C}$ and 15 days respectively for bacteria and fungi. The lowest concentration of each extract in each treatment, showing no visible growth after incubation under conditions as mentioned above were recorded as MIC values. 


\section{Determination of antioxidant activities DPPH radical scavenging assay}

Test samples were allowed to react with stable free radical, 1, 1-Diphenyl-2-picrylhydrazyl radical (DPPH) (from Sigma Aldrich) for half an hour at $37{ }^{\circ} \mathrm{C}$. The concentration of DPPH was kept as $300 \mu \mathrm{M}$. The test samples $(500 \mu \mathrm{g} / \mathrm{ml})$ were dissolved in DMSO while the DPPH solution was prepared in ethanol. Propyl gallate was used as antioxidant standard (1 mM/ml). After incubation, decrease in absorption was measured at 515 nm using multiplate reader (Spectra MAX-340). Percent radical scavenging activity (\% RSA) by samples was determined in comparison with a DMSO treated control group. Percentage of RSA was calculated in comparison with control by using the following formula:

$$
\% \mathrm{RSA}=100-\left\{\left(\frac{\text { OD test extract }}{\text { OD control }} \times 100\right\}\right.
$$

\section{Superoxide anion scavenging assay}

Measurement of superoxide radical scavenging activity was carried out by the modified method used by Ferda (2003). The reaction mixture comprised of $40 \mathrm{ml}$ of 280 $\mathrm{mM} \beta$-nicotinamide adenine dinucleotide reduced form (NADH), $40 \mathrm{~mL}$ of $80 \mathrm{M}$ nitro blue tetrazolium (NBT), $20 \mathrm{~mL}$ phenazine methosulphate (PMS) $10 \mathrm{~mL}$ of $1 \mathrm{mM}$ sample and $90 \mathrm{~mL}$ of $0.1 \mathrm{M}$ phosphate buffer ( $\mathrm{pH} 7.4)$. Reagents were prepared in buffer solution and the sample in DMSO. The reaction was performed in a 96-well microtiter plate at room temperature and absorbance was measured at $560 \mathrm{~nm}$. The formation of superoxide was monitored by measuring the formation of watersoluble blue formazan dye. A lower absorbance of reaction mixture indicates a higher scavenging activity of the sample. The percentage of RSA was determined in comparison with control by using formula as mentioned above in DPPH assay.

\section{Metal chelation assay}

The $\mathrm{Fe}^{+2}$-chelating activity was determined according to the modified method of Kexue et al., (2006). The Fe ${ }^{+2}$ was monitored by measuring the formation of ferrous ionferrozine complex. The extract $(500 \mu \mathrm{g} / \mathrm{ml})$ was mixed with $0.0625 \mathrm{mM} \mathrm{FeSO}_{4}$ and $0.5 \mathrm{mM}$ ferrozine then mixture was shaken, and left at room temperature for 10 min. The absorbance of resulting mixture was measured at $562 \mathrm{~nm}$. A lower absorbance of reaction mixture indicated a higher $\mathrm{Fe}^{+2}$-chelating ability. EDTA (1mM) was used as $\mathrm{Fe}^{+2}$-chelating standard. The percentage of
$\mathrm{Fe}^{+2}$-chelating activity was calculated in comparison with a control by using the formula as mentioned above in DPPH assay.

\section{Urease inhibition assay}

Urease activity was determined by measuring ammonia production using the indophenol method as described by Weatherburn (1967). Reaction mixtures $(200 \mu \mathrm{l})$ at $\mathrm{pH}$ 6.8 comprising $25 \mu \mathrm{l}$ of urease (jack bean) solution and 55 $\mu \mathrm{l}$ of buffers containing $100 \mathrm{mM}$ urea were incubated with $5 \mu \mathrm{l}$ of the test extract $(500 \mu \mathrm{g} / \mathrm{ml})$ at $30{ }^{\circ} \mathrm{C}$ for $15 \mathrm{~min}$ in 96-well plates. $45 \mu \mathrm{l}$ phenol reagent ( $1 \% \mathrm{w} / \mathrm{v}$ phenol and $0.005 \% \mathrm{w} / \mathrm{v}$ sodium nitroprusside) and $70 \mu \mathrm{l}$ of alkali reagent $(0.5 \% \mathrm{w} / \mathrm{v} \mathrm{NaOH}$ and $0.1 \%$ active chloride $\mathrm{NaOCl}$ ) were added to each well. Thiourea was used as the standard inhibitor of urease. The increasing absorbance was measured at $630 \mathrm{~nm}$ after $50 \mathrm{~min}$, using a microplate reader as mentioned above. The results from five observations were processed by using softMax Pro software (Molecular Device, USA). Percentage inhibitions were calculated from the formula as mentioned above in DPPH assay.

\section{Anthelmintic activity}

The anthelmintic assay was carried according to the method of Ajaiyeoba et al., (2001). Five adult earthworms (Pheritima posthuma) were released into $50 \mathrm{ml}$ solutions of three different concentrations $(20,50$ and $100 \mathrm{mg} / \mathrm{ml}$ each) of control drugs (Piperazine citrate, Albendazole), extracts from leaves and distilled water. Observations were made for the time taken to set paralysis (P) and death (D) of individual worms. Time for paralysis was noted when no movement of any sort could be observed except when the worms were shaken vigorously. Death was concluded when the worms neither moved when shaken vigorously nor when dipped in warm $\left(60{ }^{\circ} \mathrm{C}\right)$ followed with fading away of their body colors.

\section{Statistical analysis}

Antimicrobial and antioxidant activities of each extract were expressed as mean \pm standard error of mean (SEM) of five observations. Data of each extract were separately analyzed using the one-way analysis of variance followed by the student-Waller Ducan test at $\mathrm{P}<0.05$ significance level. A statistical package (CoHort version-6) was used for the data analysis. 


\section{RESULTS}

\section{Phytochemical screening}

Phytochemical analysis qualitatively investigated that extracts from leaves of two indigenous fruiting plants $M$. indica and M. alba were found to contain biologically active compounds which have been reported to serve as potential plant drugs in herbal medicine. Among the tested leaf extracts, in that of $M$. indica, steroid, anthraquinones and cardiac glycosides, and in M. alba phlobatannin and terpenoids were not detected (Table
1). Further, AEs, DEs and MEs from M. indica and M. alba were found to contain only 5 and 6, 9 and 10, and 8 to 9 tested phytochemical groups, respectively. These results substantiated the several reports on phytochemical analysis of plant leaves that plants contain various extractable bioactive secondary metabolite compounds such as phenols, terpenoids, tannins, alkaloids, flavonoids, steroids, and glycosides etc in appreciable quantities for defense and physiological activities (De and James 2002; Mallikharjuna et al., 2007).

Table 1. Phytochemicals in leaves of Mangifera indica and Morus alba.

\begin{tabular}{lcccccc}
\hline \multirow{2}{*}{ Phytochemicals } & \multicolumn{3}{c}{ Mangifer indica } & \multicolumn{4}{c}{ Morus alba } \\
\cline { 2 - 7 } & AE & DE & ME & AE & DE & ME \\
\hline Carbohydrates & + & + & - & + & + & - \\
Alkaloids & - & + & + & + & + & + \\
Phenols & + & + & + & + & + & + \\
Flavonoids & + & + & + & + & + & + \\
Terpenoids & - & + & + & - & - & - \\
Saponins & - & + & + & - & + & + \\
Tannins & + & + & + & - & + & + \\
Steroids & - & - & - & + & + & + \\
Resins & + & + & + & + & + & + \\
Anthraquinones & - & - & - & - & + & + \\
Cardiac glycosides & - & - & - & - & - & - \\
Phlobatannins & - & + & + & & + & + \\
\hline
\end{tabular}

AE aqueous extract, DE DMSO extract, ME methanol extract, + present, - absent.

\section{In-vitro Biological activities}

Based on the presence of bioactive phytochemical groups all leaf extracts were tested for in-vitro biological activities such as antimicrobial, antioxidant, urease inhibition and anthelmintic.

\section{Antibacterial activity}

When the efficacy of these extract were tested in-vitro against eleven strains of human pathogenic bacteria, all extract were found to exhibit statistically significant $(\mathrm{P}<$ 0.05 ) activity on all the test Gram-positive and -negative bacteria producing zone of inhibition ranging from $15 \pm 0.57$ to $43.66 \pm 0.66 \mathrm{~mm}$ against $S$. tyhpimurium and $P$. aeruginosa by AE from $M$. indica and DE from M. alba respectively except $\mathrm{AE}$ from $M$. indica which could not inhibit the growth of B. subtilis, B. cereus, H. pylori, $K$. pneumoniae and $S$. flexenari (Table 2). Among extracts, $\mathrm{AE}$ and DE from $M$. indica significantly inhibited the $S$. aureus whereas ME was significant against E. coli. Similarly, among M. alba extracts, the antibacterial activity of $\mathrm{AE}$ and ME was significant against $S$. typhimurium and $P$. aeruginosa respectively and that of DE was significant against B. cereus and P. aeruginosa (Table 2). AE from $M$. alba and $M$. indica showed the minimum inhibition activity against $B$. subtilis and $S$. tyhpimurium respectively. Similarly, DE and ME from both M. indica and $M$. alba showed the least activity against $K$. pneumoniae and $S$. flexenari respectively (Table 2). The spectra of antibacterial activities displayed by these extracts were explained by the presence of biologically potent antibacterial phytochemicals such as flavonoids, tannins, saponins steroids, phenolic acids, anthocyanins, alkaloids and terpenoids in leaves of these two indigenous fruiting plants (Hu 2000; Vaghasya et al., 2011). The activity of extracts against the Gram-negative (E. coli, H. pylori $P$. aeruginosa, $S$. flexenari, $K$. pneumoniae and $S$. typhimurium) is impressive because Gram-negative bacteria tend to have higher intrinsic resistance to most antimicrobial agents (Ndukwe et al., 2005). On the other hand, activity against Gram-positive bacteria especially 
cocci are interesting as they still predominate as a cause of nosocomial- and community-acquired infections. Additionally, these bacteria are able to acquire resistance to frequently used drugs rapidly through selective pressure of the environment and via the genetic evolution of bacteria (eljaszewicz et al., 2000).

\section{Antifungal activity}

E xtracts from leaves of both selected fruiting plants also showed the statically significant $(\mathrm{P}<0.05)$ activity against all six tested human pathogenic fungal strains producing zone of inhibition ranging from $9 \pm 0.57$ to $34 \pm 0.57 \mathrm{~mm}$ against $C$. glabberata and $F$. solani by AE and DE from $M$. alba respectively except $\mathrm{AE}$ from $M$. indica which could not inhibit the $M$. canis whereas $\mathrm{AE}$ and $\mathrm{DE}$ from M. alba did not the M. canis and F. solani, and A. flavus respectively. Within the various tested extracts, DE and ME from both plants the maximum activity against $F$. solani. Similarly, AE from both plants was found to have maximum activity against $A$. flavu, (Table 2 ). The minimum activity showed by DE from $M$. indica was against $T$. longifusu whereas that from M. alba was against C. albicans. The minimum fungal inhibition by AE and ME from both selected plants was against $C$. glabberata (Table 2). These results showed correlation with those of several reports on synthesis of antifungal substances by plants in response to microbial attack and it should not be surprising that they have been found to be still effective against a wide array of pathogenic microorganisms, when tested in-vitro (Idris et al., 2009; Kanwal et al., 2010; Tiwari et al., 2011a).

Table 2. Antimicrobial activity of extracts from leaves of Mangifera indica and Morus alba.

\begin{tabular}{lcccccc}
\hline & \multicolumn{7}{c}{ Zone of inhibition (mm) } \\
\cline { 2 - 7 } Microbial pathogens & \multicolumn{3}{c}{ Mangifera indica } & \multicolumn{3}{c}{ Morus alba } \\
\cline { 2 - 7 } & $\mathrm{AE}$ & $\mathrm{DE}$ & $\mathrm{ME}$ & $\mathrm{AE}$ & $\mathrm{DE}$ & $\mathrm{ME}$ \\
\hline Bacillus subtilis & $\mathrm{NI}$ & $25.00 \pm 0.57$ & $23.33 \pm 0.88$ & $20.66 \pm 0.88$ & $37.00 \pm 0.57$ & $29.00 \pm 0.57$ \\
B. cereus & $\mathrm{NI}$ & $31.33 \pm 1.20$ & $21.00 \pm 1.00$ & $24.00 \pm 1.00$ & $42.33 \pm 0.33$ & $31.66 \pm 0.66$ \\
Escherichia coli & $19.66 \pm 1.20$ & $22.66 \pm 0.33$ & $37.33 \pm 0.33$ & $25.66 \pm 0.66$ & $36.00 \pm 0.57$ & $26.00 \pm 0.57$ \\
Helicobacter pylori & $\mathrm{NI}$ & $29.00 \pm 0.57$ & $23.34 \pm 0.57$ & $32.00 \pm 0.88$ & $35.00 \pm 0.57$ & $33.00 \pm 1.2$ \\
Klebsiella pneumoniae & $\mathrm{NI}$ & $20.66 \pm 0.88$ & $33.33 \pm 0.88$ & $24.66 \pm 1.33$ & $29.33 \pm 0.88$ & $34.00 \pm 0.57$ \\
Pseudomonas aeruginosa & $17.33 \pm 0.66$ & $21.33 \pm 1.66$ & $30.00 \pm 0.57$ & $32.66 \pm 0.88$ & $43.66 \pm 0.66$ & $36.66 \pm 0.88$ \\
Salmonella typhimurium & $15.00 \pm 0.57$ & $29.33 \pm 0.88$ & $28.66 \pm 1.20$ & $43.00 \pm 0.57$ & $35.66 \pm 0.88$ & $32.00 \pm 1.15$ \\
Shigella flexenari & $\mathrm{NI}$ & $33.33 \pm 1.20$ & $20.66 \pm 1.20$ & $32.66 \pm 0.66$ & $35.33 \pm 0.88$ & $24.33 \pm 0.88$ \\
Staphylococcus aureus & $24.00 \pm 1.15$ & $35.33 \pm 0.33$ & $30.66 \pm 0.66$ & $17.66 \pm 0.66$ & $36.33 \pm 0.88$ & $31.00 \pm 0.57$ \\
S. pyogenes & $21.66 \pm 0.66$ & $31.33 \pm 0.66$ & $33.33 \pm 1.20$ & $25.00 \pm 1.00$ & $33.66 \pm 0.66$ & $26.66 \pm 1.20$ \\
S. pneumoniae & $21.00 \pm 1.52$ & $30.00 \pm 0.57$ & $29.00 \pm 0.57$ & $36.33 \pm 0.33$ & $35.00 \pm 0.57$ & $25.00 \pm 0.57$ \\
Trichophyton longifusus & $14.66 \pm 0.66$ & $15.00 \pm 0.57$ & $19.00 \pm 0.57$ & $14.33 \pm 0.88$ & $23.00 \pm 0.57$ & $29.66 \pm 0.33$ \\
Candida albicans & $12.00 \pm 0.57$ & $14.33 \pm 0.88$ & $17.33 \pm 0.33$ & $11.00 \pm 0.57$ & $17.00 \pm 0.57$ & $18.66 \pm 0.88$ \\
Aspergilus flavus & $21.33 \pm 0.33$ & $18.33 \pm 0.33$ & $21.33 \pm 0.33$ & $17.66 \pm 0.33$ & $20.66 \pm 0.33$ & $25.33 \pm 0.88$ \\
Microsporum canis & $\mathrm{NI}$ & $15.66 \pm 0.88$ & $18.33 \pm 0.33$ & $\mathrm{NI}$ & $\mathrm{NI}$ & $14.66 \pm 0.33$ \\
Fusarium solani & $13.66 \pm 0.66$ & $21.00 \pm 0.57$ & $23.00 \pm 0.57$ & $\mathrm{NI}$ & $34.00 \pm 0.57$ & $30.00 \pm 1.00$ \\
Candida glabberata & $10.33 \pm 0.66$ & $17.33 \pm 0.33$ & $14.00 \pm 0.57$ & $9.00 \pm 0.57$ & $25.00 \pm 0.57$ & $12.33 \pm 1.33$ \\
\hline
\end{tabular}

NI: no inhibition.

\section{Minimum inhibitory concentration}

The results of MIC showed that the least concentrations of all tested potent extracts required for inhibition of test bacterial pathogens were in range of $13 \pm 1.64$ (ME from M. alba against $S$. aureus) to $100 \pm 0.35 \mathrm{mg} / \mathrm{ml}$ (AE from $M$. alba against $S$. flexenari) $\mathrm{mg} / \mathrm{ml}$. However, among all potent extracts ME from $M$. indica, DE and ME from $M$. alba had the lowest MIC value against six (E. coli, $K$. pneumoniae, S. tyhpimurium, S. flexenari, S. pyogenes and
S. aureus), two (S. pneumoniae and B. cereus) and ( $P$. aeruginosa, $H$. pylori and $B$. subtilis) test bacterial pathogens respectively, thus indicating a high potency (Table 3). Similarly, the MIC values against test fungal pathogens were found in range of $23 \pm 1.25$ (DE from $M$. indica against $A$. flavus) to $115 \pm 0.55 \mathrm{mg} / \mathrm{ml}$ (AE from $M$. indica against $C$. glabberata) $\mathrm{mg} / \mathrm{ml}$. Among all fungicidal extracts, only DE and ME from $M$. indica and $M E$ from $M$. albademonstrated the least MIC values against one $(A$. 
flavus) and two (F. solani and C. glabberata), and three ( $T$. longifusus, C. albicans and M. canis) respectively, thus indicating a high potency among tested crude extracts (Table 3). Although the antimicrobial activities of these tested extracts were found to be less as compared to standard antimicrobials, may be due to the fact that it was crude and required further purification. However, still can play significant roles in medical health care implementation locality for treatment and control of diseases in nearly, all cultures and civilizations specially developing countries of the world because of their effectiveness, affordability, availability, low toxicity and acceptability (Akharaiyi and Boboye 2010; Tiwari et al., 2011a). Further, among all three extracts, those of DMSO and methanol from leaves of both local fruiting plants were found to have a comparatively higher potency than water extracts but still there are variations in the antimicrobial potency (inhibitory zones) and MIC values of the plants extracts. These variations could be attributed to the varying presence pattern and combination of active phytochemicals, varying concentrations, and also depending on differences in growth rate of the tested organisms, nutritional requirements, temperature and inoculum size acceptability (Gaill and Jon 1995; Akharaiyi and Boboye 2010). Differences in polarity among the various solvents might also be responsible for the differences in solubility of plant active principles, hence the variation in degree of activity (Idris et al., 2009).

Table 3. Minimal inhibition concentration of extracts from leaves of Mangifera indica and Morus alba.

\begin{tabular}{lcccccc}
\hline \multirow{2}{*}{ Microbial pathogens } & \multicolumn{3}{c}{ Mangifera indica $(\mathrm{mg} / \mathrm{ml})$} & \multicolumn{3}{c}{ Morus alba $(\mathrm{mg} / \mathrm{ml})$} \\
\cline { 2 - 7 } & $\mathrm{AE}$ & $\mathrm{DE}$ & $\mathrm{ME}$ & $\mathrm{AE}$ & $\mathrm{DE}$ & $\mathrm{ME}$ \\
\hline Bacillus subtilis & $\mathrm{NT}$ & $65 \pm 1.5$ & $55 \pm 0.53$ & $80 \pm 0.35$ & $45 \pm 0.28$ & $44 \pm 1.36$ \\
B. cereus & $\mathrm{NT}$ & $65 \pm 1.65$ & $60 \pm 1.25$ & $80 \pm 0.66$ & $18 \pm 0.63$ & $45 \pm 1.25$ \\
Escherichia coli & $80.66 \pm 1.76$ & $70 \pm 1.37$ & $35 \pm 0.54$ & $75 \pm 0.84$ & $45 \pm 0.84$ & $64 \pm 0.46$ \\
Helicobacter pylori & $\mathrm{NT}$ & $50 \pm 1.45$ & $55 \pm 1.85$ & $40 \pm 1.27$ & $34 \pm 1.33$ & $32 \pm 1.23$ \\
Klebsiella pneumoniae & $\mathrm{NT}$ & $36 \pm 0.45$ & $30 \pm 0.78$ & $80 \pm 0.55$ & $60 \pm 1.5$ & $48 \pm 0.75$ \\
Pseudomonas aeruginosa & $70 \pm 1.45$ & $63 \pm 0.56$ & $30 \pm 1.35$ & $60 \pm 1.85$ & $40 \pm 1.42$ & $15 \pm 1.35$ \\
Salmonella typhimurium & $50 \pm 0.88$ & $69 \pm 0.78$ & $35 \pm 1.48$ & $74 \pm 1.48$ & $43 \pm 1.18$ & $40 \pm 0.55$ \\
Shigella flexenari & $\mathrm{NT}$ & $48 \pm 0.57$ & $40 \pm 1.27$ & $100 \pm 0.35$ & $45 \pm 0.66$ & $55 \pm 1.56$ \\
Staphylococcus aureus & $76 \pm 0.88$ & $55 \pm 0.27$ & $13 \pm 1.64$ & $67 \pm 0.56$ & $38 \pm 1.75$ & $46 \pm 1.64$ \\
S. pyogenes & $77 \pm 0.57$ & $58 \pm 0.27$ & $30 \pm 1.44$ & $84 \pm 0.44$ & $40 \pm 0.67$ & $50 \pm 0.67$ \\
S. pneumoniae & $77 \pm 0.57$ & $65 \pm 0.45$ & $50 \pm 0.75$ & $45 \pm 1.47$ & $32 \pm 0.88$ & $60 \pm 1.34$ \\
Trichophyton longifusus & $85 \pm 0.35$ & $75 \pm 0.48$ & $70 \pm 1.76$ & $90 \pm 1.27$ & $50 \pm 1.24$ & $30 \pm 0.76$ \\
Candida albicans & $97 \pm 1.34$ & $85 \pm 1.55$ & $60 \pm 0.35$ & $100 \pm 0.65$ & $75 \pm 0.25$ & $53 \pm 1.15$ \\
Aspergilus flavus & $68 \pm 0.33$ & $23 \pm 1.25$ & $47 \pm 1.46$ & $64 \pm 1.33$ & $69 \pm 0.45$ & $48 \pm 0.26$ \\
Microsporum canis & $\mathrm{NT}$ & $70 \pm 1.45$ & $55 \pm 0.56$ & $\mathrm{NT}$ & $\mathrm{NT}$ & $48 \pm 0.76$ \\
Fusarium solani & $95 \pm 0.54$ & $45 \pm 1.75$ & $25 \pm 1.35$ & $\mathrm{NT}$ & $33 \pm 1.55$ & $50 \pm 1.26$ \\
Candida glabberata & $115 \pm 0.55$ & $75 \pm 1.23$ & $60 \pm 0.56$ & $105 \pm 1.26$ & $65 \pm 0.55$ & $83 \pm 1.22$ \\
\hline
\end{tabular}

NT: not tested

\section{Antioxidant activities}

The decrease in absorbance produced by reduced DPPH was used to evaluate the ability of test extracts to act as free radical scavengers. The DPPH results showed that all extracts from leaves of both fruiting plants had DPPH free radical scavenging activity ranging from $13.68 \pm 0.74$ to $93.70 \pm 0.76 \%$ by AE from $M$. alba and ME from $M$. indica respectively. Among all tested extracts, ME from $M I$, and $\mathrm{DE}$ and ME from $M$. alba were found to be significantly active against DPPH free radical with scavenging activity higher than that of standard antioxidant propyl gallate.
The scavenging effects of extracts on DPPH radical have demonstrated the hydrogen donating ability on reaction with DPPH radical. Earlier reports on similar studies also showed that the reduction mechanism of DPPH correlated with the presence of hydroxyl groups on the antioxidant molecules (Aliyu et al., 2009). All extracts from leaves of both fruiting plants were also found to be active against superoxide anion radical with activity ranging from $50.23 \pm 0.43$ to $95.7 \pm 0.21 \%$ by DE from $M$. alba and AE from $M$. indica respectively. Superoxide anion RSA of AE and DE from M. indica and ME from $M$. alba 
were not only found to be higher than that of standard superoxide anion radical scavenger propyl gallate (91.31\%). Similar studies correlated the superoxide anion radical scavenging activities of plant extracts to the presence of phenols which was true for present investigation. Hence, these extracts could be used as natural sources of antioxidants against superoxide radicals to protect animals from adverse effects of $\mathrm{O}_{2}$ (AlMamun et al., 2007). From results of the metal-chelating assay, it was clear that all three test extracts from leaves of both fruiting plants inhibited the formation of ferrozine- $\mathrm{Fe}^{2+}$ complex giving $\mathrm{Fe}^{+2}$ chelating activity ranging from $52.76 \pm 0.23$ to $96.82 \pm 0.42 \%$ by DE from $M$. indica and ME from $M$. alba respectively. Among all extracts, ME from $M$. alba exhibited the maximum activity which surpassed the that by standard $\mathrm{Fe}^{+2}$ chelating agent EDTA. Since, ferrozine can quantitatively form complexes with $\mathrm{Fe}^{2+}$. In the presence of other chelating agents, the complex formation is disrupted with the result that the red color of the complex is decreased. Measurement of the rate of red color reduction, therefore, allows estimation of the chelating activity of the coexisting chelator radicals (Wang et al., 2010). This suggested that the leave extract were electron donors and could neutralize free radicals. Considering the phytochemical screening, the DPPH and superoxide anion radical scavenging, and metal-chelating activity as indices of antioxidant activity of the extract, these findings revealed the therapeutic potential of leaves of under studied fruiting plants as a source for local natural antioxidants in controlling degenerative diseases with marked oxidative damage from reactive oxygen species or free radicals have been reported (Tiwari et al., 2011b).

Table 4. Antioxidant activities of extract from leaves of Mangifera indica and Morus alba.

\begin{tabular}{lcccc}
\hline \multirow{2}{*}{ Sample } & \multirow{2}{*}{ Extract } & \multicolumn{3}{c}{ \% Activity (mean \pm SEM) } \\
\cline { 3 - 5 } & & DPPH RSA & Superoxide RSA & $\mathrm{Fe}^{+2}$-chelation \\
\hline Mangifera indica & $\mathrm{AE}$ & $68.47 \pm 0.32$ & $95.7 \pm 0.21$ & $65.55 \pm 0.45$ \\
& $\mathrm{DE}$ & $74.64 \pm 1.87$ & $94.30 \pm 0.87$ & $52.76 \pm 0.23$ \\
Morus alba & $\mathrm{ME}$ & $93.70 \pm 0.76$ & $75.56 \pm 1.11$ & $76.45 \pm 1.33$ \\
& $\mathrm{AE}$ & $13.68 \pm 0.74$ & $54.65 \pm 0.89$ & $55.40 \pm 1.23$ \\
& $\mathrm{DE}$ & $92.24 \pm 0.85$ & $50.23 \pm 0.43$ & $71.12 \pm 0.70$ \\
n-propyl gallate & $\mathrm{ME}$ & $91.55 \pm 1.06$ & $92.12 \pm 1.86$ & $96.82 \pm 0.42$ \\
EDTA & & 91.31 & 91.31 & \\
\hline
\end{tabular}

\section{Urease inhibition}

E xcept AE from $M$. indica all extracts from each plant leaves inhibited the urease activity from moderate to significant in the range of 75 to $95.23 \%$ by AE and DE from $M$. alba respectively. DE from Among potent extracts, DE from $M$. alba was found to significantly inhibited the urease activity which is comparable with that shown by standard urease inhibitor thiourea (Figure 1) Urease inhibition by theses leaves extracts further explained their antibacterial activity against $H$. pylori.
These antiurease results provide a scientific basis for the traditional use of these plants crude extracts to treat diseases caused by the accumulation of urea and against gastrointestinal and urinary tract infection associated with pathogenic strains of $H$. pylori, P. mirabilis, $P$. vulgaris, and U. urealyticum (Estiu and Merz 2004; Tahseen et al., 2010; Khan et al., 2010). Further, these crude extracts also provide a reliable source for isolation of pure antiurease compounds at affordable prices (Tahseen et al., 2010). 


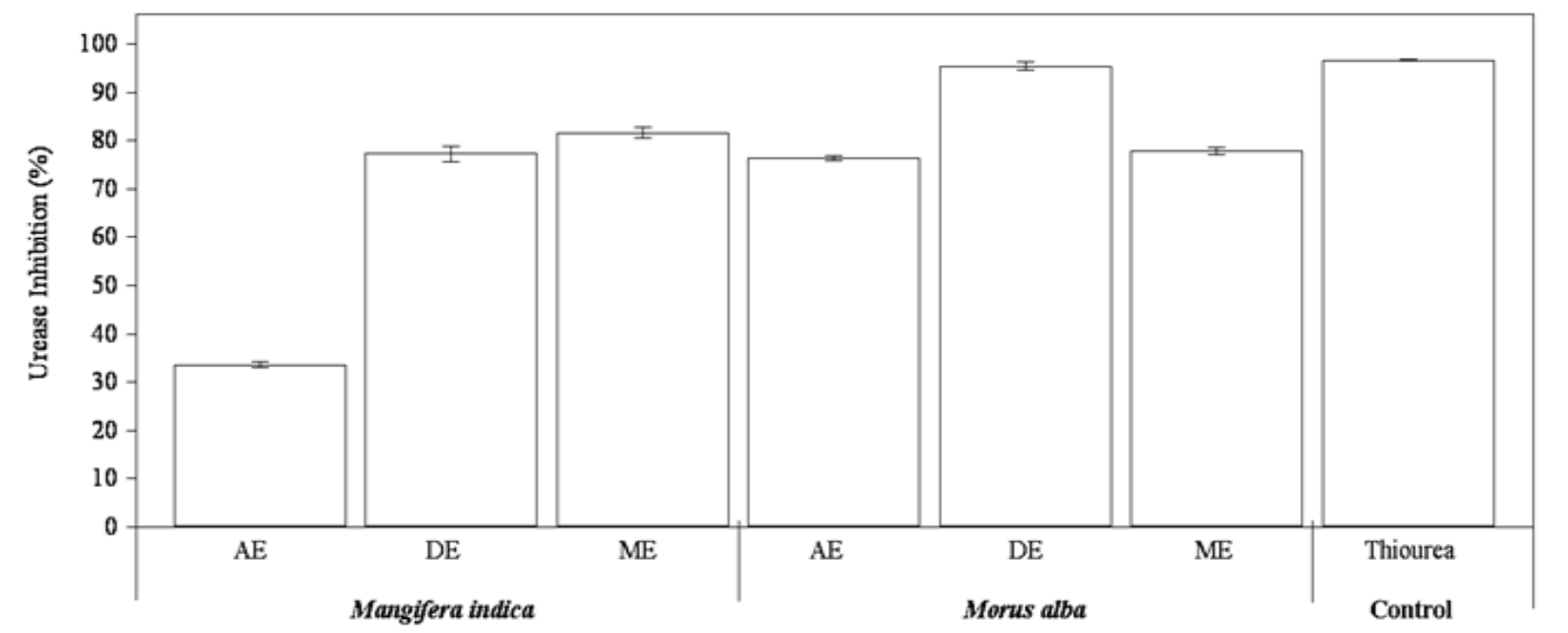

Figure. 1. Urease inhibition activity of extract from leaves of Mangifera indica and Morus alba.

\section{Anthelmintic activity}

The assay was performed on adult earth worms ( $P$. pasthuma) due to anatomical and physiological resemblance with intestinal round worms parasite in soil and as well as their easy availability. From results shown in Figure 2, it is clear that all test leaves extract from both fruiting plants caused paralysis followed by the subsequent death of the worms in period ranging from $13.5 / 26.87$ to 39/60.06 min for paralysis and death (P/D). The time taken by ME from M. indica and M. alba for paralysis and death (13.5/26.87 and 14.05 / 34.45 mint respectively) of parasite is least among all tested extract as well as standard drugs, albendazole (30.45/52 $\mathrm{min}$ ) and less than piperazine citrate (14.35/36 $\mathrm{min})$, thus signifying the highest efficacy (Figure 2). While the time taken by AE from both M. indica and M. alba, and DE from M. alba for paralysis and death is 35.8/53.04, $39 / 50.06$ and $31.22 / 54.17$ min respectively which are higher than that of all tested extract and standard drugs thus suggesting the least activity against helminthes parasites. On the other hands, only DE from M. indica took 22.2/37.76 $\mathrm{min}$ for paralysis and death respectively suggesting their potency higher than albendazole and less than piperazine citrate (Figure 2). Several earlier studies revealed the in vitro anthelmintic activities of flavonoids, saponins, steroids, sugars, terpenoids, alkaloids, tannins, saponins and phenols extracted from plants. Such investigations are true for in vitro anthelmintic activities on extracts from under studied plants. Moreover, the length of time taken for paralysis and death may be dependent on concentrations and the number of potent phyto-constituents present in the plant, jointly or separately. As control anthelmintic drug piperazine citrate by increasing chloride conductance of worm muscle membrane produces hyper polarisation and reduced excitability that leads to muscle relaxation and flaccid paralysis. Similarly, among the screened phytochemicals, the possible mechanism of action of tannins and polyphenolics might interfere with energy generation by uncoupling oxidative phosphorylation by binding to glycoprotein on the cuticle of the parasite and may cause death. The main biological activity ascribed to saponins was their membrane permeabilizing and pore formation, which is similar to two conventional anthelmintic drugs such as praziquantel and toltrazuril (Kulkarni et al., 2010; Tiwari et al., 2011b). Alkaloids may act on central nervous system and caused paralysis of the earthworm (Roy 2010). 


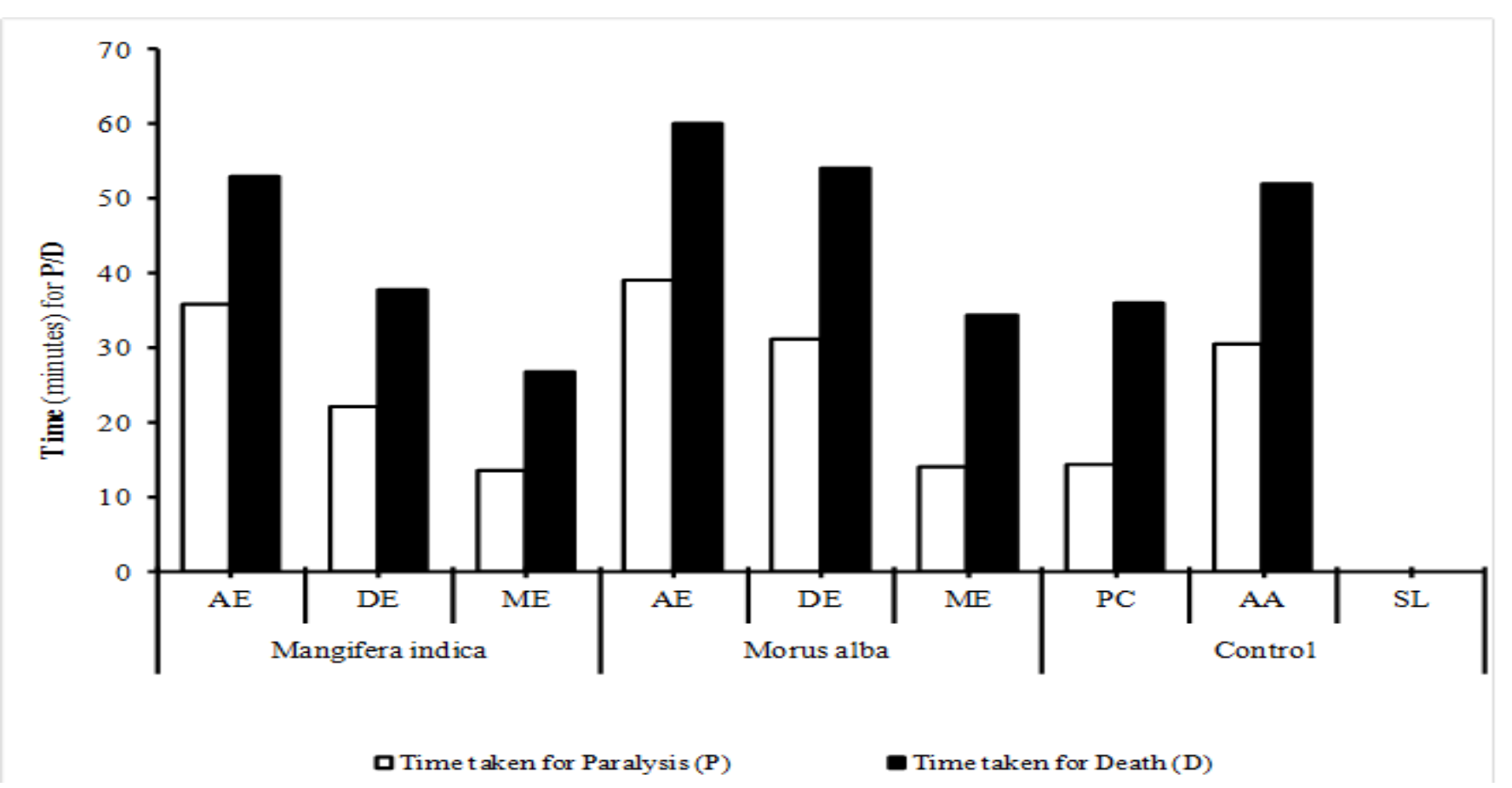

Figure. 2. Anthelmintic activity of extract from leaves of Mangifera indica and Morus alba.

PC: Piperazine citrate; AA: Albendazole; SL: saline

\section{CONCLUSIONS}

It can be concluded that leaves from indigenous fruiting plants M.indica and M. alba that considered as waste were found to contain a wide variety of antibacterial, antifungal, antioxidant, urease inhibitory and anthelmintic compounds. The broad spectra of antimicrobial and antioxidant, urease inhibition and anthelmintic activities displayed by these extracts explain that the purified components may have even more potency. The potent activity of extracts warrants further investigation and rapid development to add to the list of currently available pharmacological agents. Certainly, this may improve the efficacy and quality at affordable prices to decrease morbidity and mortality. The present findings provide scientific justification for the ethnomedicinal use of selected plant's leaves for treatment and controlling of infectious and degenerative diseases especially in less developing and third world countries, where infectious diseases caused by bacteria, fungi and parasites, and degenerative diseases are major health concern due to unavailability and unaffordability of modern treatments. These results also validate the traditional use of these extracts for the treatment of infectious and degenerative diseases.

\section{CONFLICT OF INTEREST}

The authors declare that they have no conflicts of interest.

\section{AUTHORS CONTRIBUTIONS}

All the authors contributed equally to this work.

\section{REFERENCES}

Ajaiyeoba, E.O., P.A. Onocha, and O.T. Olarenwaju. 2001. In-vitro anthelmintic properties of Buchholzia coriaceae and Gynandropsis gynandra extract. Pharmaceutical biology, 39(3): 217-220.

Akharaiyi, F.C. and B. Boboye. 2010. Antibacterial and phytochemical evaluation of three medicinal plants. Journal of Natural Products, 3: 27-34.

Aliyu, A.B., A.M. Musa, M.A. Ibrahim, H. Ibrahim and A.O. Oyewale. 2009. Preliminary phytochemical screening and antioxidant activity of leave extract of Albizia chevalieri harms (Leguminoseaemimosoideae). Bayero Journal of Pure and Applied Sciences, 2(1): 149 -153.

Al-Mamun, M., K. Yamaki, T. Masumizu, Y. Nakai, K. Saito, H. Sano and Y. Tamura. 2007. Superoxide anion radical scavenging activities of herbs and pastures in Northern Japan determined using electron spin resonance spectrometry. International Journal of Biological Sciences, 3(6): 349-355. 
Anyasor, G.N., K.O. Ogunwenmo, O.A. Oyelana and B.E. Akpofunure. 2010. Phytochemical constituents and antioxidant activities of aqueous and methanol stem extracts of Costus afer Ker Gawl. (Costaceae), African Journal of Biotechnology, 9(31): 48804884.

Coolborn, A.F. and B. Bolatito. 2010. Antibacterial and phytochemical evaluation of three medicinal plants. Journal of Natural Products, 3: 27-34.

Cunha, B. 1998. Antibiotic resistance: control strategies, Critical Care Clinics, 14(2): 309-327.

De, N. and N.E. James. 2002. Antibacterial spectrum of ectracts of Ocimum gratissimum L (Basil) ND Xylopia aetiopica A. Rich (Dunal). Nigerian Journal or Basic and Applied Sciences, 11: 165-175.

Devi, K., S. Indumathy, V. Rathinambal, S. Uma, S. Kavimani and V. Balu. 2009. Anthelminthic activity of Asta Churna. International Journal of Health Research, 2(1): 101-103.

Doughari, J.H. and S. Manzara. 2008. In-vitro antibacterial activity of crude leaf extracts of Mangifera indica Lin, African Journal of Microbiology Research, 2(4): 67-72.

Duru, C.M. and N.E. Oyedineke. 2010. In-vitro study on antimicrobial activity and phytochemical analysis of ethanolic extracts of the mesocarp pf Voacanga Africana, American Journal of Plant Physiology, 5(4): 63-169.

Estiu, G. and K.M. Merz. 2004. The Hydrolysis of urea and the proficiency of urease. Journal of the American Chemical Society, 126(22): 6932-6944.

Fazly-Bazzaz, B.S., M. Khajehkaramadin and H.R. Shokooheizadeh. 2005. In vitro antibacterial activity of Rheum ribes extract obtained from various plant parts against clinical isolates of Gram-negative pathogens. Iranian Journal of Pharmaceutical Research, 2: 87- 91.

Ferda, C. 2003. Effect of Rhus coriaria (anacardiaceae) on superoxide radical scavenging and xanthine oxidase activity. Journal of Enzyme Inhibition and Medicinal Chemistry, 18(1): 59-62.

Gaill, W. and A.W. Jon. 1995. Antimicrobial susceptibility test; dilution and disc diffusion methods, Manual of Clinical Microbiology, sixth ed.1327-1332.

Tahseen, G., A. Kalsoom, N. Faiz-ul-Hassan and M.A. Choudhry. 2010. Screening of selected medicinal plants for urease inhibitory activity. Biology and Medicine, 2(4): 64-69.
Hu, F.B. 2000. Role of antioxidants in preventing cardiovascular disease. Current Opinion in Lipidology, 13: 3.

Idris, S., G.I. Ndukwe and C.E. Gimba. 2009. Preliminary phytochemical screening and antimicrobial activity of seed extracts of Persea americana (Avocado pear). Bayero Journal of Pure and Applied Sciences, 2(1): 173-176.

Iwu, M.W., A.R. Duncan and C.O. OKunji. 1999. New antimicrobials of plant origin. In: Janick J. (Ed.), Perspectives on New Crops and New Uses, ASHS Press, Alexandria, VA, 457-462.

Jeljaszewicz, J., G. Mlynarczyk and A. Mlynarczyk. 2000. Antibiotic resistance in Gram-positive cocci. International journal of antimicrobial agents, 16(4): 473-478.

Kanwal, Q., I. Hussain, H.L. Siddiqui and A. Javaid. 2010. Antifungal activity of flavonoids isolated from mango (Mangifera indica L.) leaves. Natural Product Research, 24(20): 1907-1914.

Karnath, L. 2002. The new paradigm of botanical drugs. European Pharmaceutical Review. 7(1): 19-20.

Kexue, Z., Z. Huiming and Q. Haifeng. 2006. Process Biochemistry, 41: 1296-1203.

Khan, I., S. Ali, S. Hameed, N.H. Rama, M.T. Hussain, A. Wadood, R. Uddin, Z. Ul-Haq, A. Khan, S. Ali and M.I. Choudhary. 2010. Synthesis, antioxidant activities and urease inhibition of some new 1,2,4-triazole and 1,3,4-thiadiazole derivatives. European journal of medicinal chemistry, 45(11): 52005207.

Kulkarni, G.K., R.V. Kadolkar and A.B. Maisale. 2010. Anthelmintic activity of Drynaria quercifolia (L.) J. Smith. Journal of Pharmacy Research, 3(5): 975977.

Mallikharjuna, P.B., L.N. Rajanna, Y.N. Seetharam and G.K. Sharanabasappa. 2007. Phytochemical studies of Strychnos potatorum L.f. A medicinal plant. EJournal of Chemistry, 4(4): 510-518.

Mathur, A., S.K. Verma, S.K. Singh, G.B.K.S. Prasad and V.K. Dua. 2010. Phytochemical investigation and in vitro antioxidant activities of some plants of uttarakhand. IJPI'S. Journal of Pharmacognosy and Herbal Formulations, 1(1): 1-7.

Muanda, F.N., J. Bouayed, A. Djilani, C. Yao, R. Soulimani and A. Dicko. 2011. Chemical composition and, cellular evaluation of the antioxidant activity of Desmodium adscendens leaves. Evidence-Based 
Complementary and Alternative Medicine, Article ID 620862, p. 9.

Ndukwe, K.C., I.N. Okeke, A. Lamikanra, S.K. Adesina and 0. Aboderin. 2005. Antibacterial activity of aqueous extracts of selected chewing sticks. Journal of Contemporary Dental Practice, 6(3): 8694.

Ospina, S., M.P. Arbeláez, L.A. Paniagua, M.C. Peláez, J.C. Ramírez and L.C. Sánchez. 2002. Factores de riezgo para infección intrahospitalaria por bacterias multiresistentes a los antibioticos. Enfermedades infecciosasy microbiologia. Infecciones nosocomiales, 22: 127.

Pourmorad, F., S.J. Hosseinimehr and N. Shahabimajd. 2006. Antioxidant activity, phenol, and flavonoid contents of some selected Iranian medicinal plants. African Journal of Biotechnology, 5(11): 11421145.

Radhika, P.B., S. Sastry and B.M. Harika. 1989. Antimicrobial screening of Andrographis paniculata (Acanthaceae) root extracts. Research Journal of Biotechnology, 3(3): 62-63.

Radhika, P.B., S. Sastry and B.M. Harika. 2008. Antimicrobial screening of Andrographis paniculata (Acanthaceae) root extracts. Research Journal of Biotechnology, 3(3): 62-63.

Rajendran, N.K. and J, Ramakrishnan. 2009. In-vitro evaluation of antimicrobial activity of crude extracts of medicinal plants against multi drug resistant pathogens. Biyoloji Bilimleri Araştırma Dergisi, 2(2): 97-101.

Roy, H. 2010. Preliminary phytochemical investigation and anthelmintic activity of Acanthospermum hispidum DC. Journal of Pharmaceutical Science and Technology, 2(5): 217-221.
Sahm, D.F. and J.A. Washington. 1990. Antibacterial susceptibility test dilutions methods, in: Manuals of clinical Microbiology, 1105-1116.

Sieradzki, K., R.B. Roberts, S.W. Haber and A. Tomasz. 1999. The development of vancomycin resistance in a patient with methicillin-resistant Staphylococcus aureus infection. The New England Journal of Medicine, 340(7): 517-523.

Sofowora. A. 1993. Medicinal plants and traditional medicine in Africa, Spectrum Books, Ibadan, p. 150.

Tiwari, P., B. Kumar, M. Kaur, G. Kaur and H. Kaur. 2011a. Phytochemical screening and extraction: A Review. International Journal of Pharmacy and Pharmaceutical Sciences, 1(1): 98-106.

Tiwari, P., B. Kumar, M. Kumar, M. Kaur, J. Debnath and P. Sharma. 2011b. Comparative anthelmintic activity of aqueous and ethanolic stem extract of Tinospora cordifolia. International Journal of Drug Development \& Research, 3(1): 70-83.

Vaghasya, Y., R. Dave and S. Chanda. 2011. Phytochemical analysis of some medicinal plants from western region of India. Research Journal of Medicinal Plants, 5(5): 567-76.

Wang, J., H. Liu, J. Zhao, H. Gao, L. Zhou, Z. Liu, Y. Chen and P. Sui. 2010. Antimicrobial and antioxidant activities of the root bark essential oil of Periploca sepium and its main component 2-hydroxy-4methoxybenzaldehyde. Molecules, 15(8): 58075817.

Weatherburn, M.W. 1967. Phenol-hypochlorite reaction for determination of ammonia. Analytical Chemistry, 39(8): 971-974.

WHO. 1995. The World Health Reports, Bridging the gap WHO, Geneva 1: 118.

Publisher's note: EScience Press remains neutral with regard to jurisdictional claims in published maps and institutional affiliations.

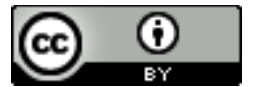

Open Access This article is licensed under a Creative Commons Attribution 4.0 International License, which permits use, sharing, adaptation, distribution and reproduction in any medium or format, as long as you give appropriate credit to the original author(s) and the source, provide a link to the Creative Commons license and indicate if changes were made. The images or other third-party material in this article are included in the article's Creative Commons license, unless indicated otherwise in a credit line to the material. If material is not included in the article's Creative Commons license and your intended use is not permitted by statutory regulation or exceeds the permitted use, you will need to obtain permission directly from the copyright holder. To view a copy of this license, visit http://creativecommons.org/licenses/by/4.0/. 